\title{
La comunidad de Mezcala y la recreación étnica ante la globalización neoliberal
}

\section{Mezcala community and ethnic recreation in neoliberal globalization}

Recibido: 16 de junio de 2011

Santiago Bastos ${ }^{1}$

Aprobado: 19 de octubre de 2011

\section{RESUMEN}

El conflicto en que está inmersa Mezcala por las amenazas a su tierra comunitaria es el marco de una renovación de la idea misma de comunidad y de los contenidos de la identidad étnica. Ante el derrumbe del sistema posrevolucionario que dio cobijo a la territorialidad de Mezcala desde la legislación agraria, las nuevas propuestas asociadas a la idea de pueblos indígenas -en este caso el Pueblo Coca- están sirviendo para renovar los derechos territoriales y de autogobierno, pero también los contenidos del ser indígena y vivir en comunidad.

Palabras clave: Comunidad, etnicidad, globalización, pueblos indígenas.

\section{ABSTRACT}

The conflict in which it is embedded Mezcala about threats to their community land is part of a renewal of the idea of community and content of ethnic identity. In face to the collapse of the postrevolutionary, which sheltered the territoriality of Mezcala, the new proposals associated with the idea of indigenous peoples-in this case Coca-Pueblo are helping to renew the land rights and self-government but also the contents of being indigenous and community life.

Key words: Community, ethnicity, globalization, indigenous people.

1 Doctor en Antropología Social, Centro de investigaciones y estudios superiores en antropología social (CIESAS), México. Correo: santiago@ciesas.edu.mx 


\section{Introducción}

El tema de "la comunidad indígena" no deja de estar presente en la agenda de investigación antropológica. Durante muchos años fue el eje desde el que se entendió la sociabilidad y cultura indígenas y en lugares como México fue la base de la acción pública (De la Peña, 1998; Sánchez, 1999). Sin embargo, llegado el final del siglo XX, las reflexiones en torno a la globalización (Appadurai, 2001 [1992]; García Canclini, 1989) y las mismas políticas públicas neoliberales auguraron el final de esta forma de sociabilidad entre los indígenas. Pero la cosa no ha sido tan fácil. Desde entonces, los mismos Pueblos Indígenas del continente se han encargado de hacer de sus espacios locales la base material e ideológica de su lucha (ver Leyva et al., 2008; Gónzalez et al., en prensa), mucha veces idealizándola (Lisbona, 2005; Bastos, 2007), pero otras, rearticulándola bajo formas nuevas (ver Bastos, 2000; Besserer, 2002, Camus, 2007, por ejemplo). Y los mismos pensadores han vuelto a acudir a esta idea para explicar lo que ocurre entre los indígenas en la globalización (Díaz Polanco, 2006).

En este artículo se quiere contribuir a esa discusión a través del caso de Mezcala de la Asunción, un poblado mexicano situado en la ribera norte del lago de Chapala, a escasos 75 kilómetros de la ciudad de Guadalajara. En los últimos años se ha enzarzado en una pugna con el gobierno para defender la integridad de sus tierras comunales. Cuando el estado patrimonial ya no asegura la defensa del territorio, los mezcalenses han echado mano de su historia y su identidad para sentirse Pueblo Coca y desde ahí reconstruir tanto el pacto comunitario como su razón de ser ante la nueva legitimidad. Esto que está ocurriendo en Mezcala puede ser un ejemplo de las dinámicas que se están desarrollando en muchas localidades de México, cuando la idea de comunidad surgida de las políticas agrarias posrevolucionarias no sirve en el contexto creado por el giro neoliberal-multicultural marcado por los cambios en los Artículos 4 y 27 constitucionales. Esa forma históricamente creada de comportamiento social que denominamos "comunidad" se está rearticulando, abriéndose la posibili- dad de una forma específica de enfrentarse y adaptarse a la globalización que puede definir el futuro de buena parte de México en este siglo que recién comienza.

Al hablar de "la comunidad" se piensa en un espacio social caracterizado por unos comportamientos colectivos, corporados según Wolf (1957), pero en que también se dan los "individualistas" supuestamente opuestos. Esta corporatividad es producto de una forma de entender las relaciones sociales que ha surgido de una historia concreta -en este caso de subordinación étnica (Bastos, 2000)-. Por ello, "la comunidad" no es un espacio idílico de relaciones horizontales, sino el escenario de conflictos, luchas y desigualdades (Zárate, 1996) que, eso sí, se dan dentro del marco comunitario de entenderlas. No se trata de un remanente de un pasado -glorioso o abyecto-, sino que se va construyendo como producto de su entorno y en estrecha relación con él. La cuestión no es tan fácil como una "comunidad" que sobrevive a los embates del Estado (Dietz, 1999) ni como la reserva de fuerzas contra la globalización neoliberal (Díaz Polanco; 2006). Como constructo histórico, esa forma de relaciones sociales que denominamos "comunidad", está siendo transformada en estos momentos: la globalización incide de tal forma en estas instituciones y comportamientos que podemos hablar de una forma comunitaria adaptada y producto del entorno global.

\section{El reconocimiento como comunidad indígena}

Mezcala obtuvo su reconocimiento como "Comunidad Indígena" a través de la Resolución Presidencial firmada por el Presidente Luis Echevarría en agosto de 1974, que "reconoce y titula a favor del poblado Mezcala una superficie de tres mil seiscientas dos hectáreas con veinte áreas", a las que declara "inalienables, imprescriptibles e inembargables" (Resolución Presidencial, 1971), de las que solo los originarios de Mezcala pueden ser propietarios, y por las que no tienen que pagar ningún tipo de contribución al Municipio.

Culminaba así un proceso iniciado casi 20 años antes, cuando, según la memoria local, una serie de ancianos y autoridades lo-

De todas formas, Castillero (ibid.) no cuestiona el hecho de que la tierra mencionada fuera poseída por Mezcala al menos desde el siglo XVI, como lo demuestran los múltiples pleitos que hubo hasta el final de la Colonia. 
cales empezaron los trámites de "reconocimiento" de las tierras de la comunidad, que estaban sufriendo los embates de las localidades vecinas y empezaban a sentir la presión inmobiliaria desde la capital.

Esta Resolución no supuso la recuperación como "restitución" de unas tierras que se hubieran perdido previamente, y tampoco implicó la "dotación" de nuevas tierras para los mezcalenses en forma de ejido. Como dice el texto, se trató "exclusivamente el de reconocer y titular las tierras que la comunidad ha venido poseyendo en forma continua, pacífica y pública desde tiempo inmemorial" (ibid.). Esta salvedad, que en el documento sirve para salvaguardar las propiedades particulares que hubiera dentro del territorio, para los mezcalenses tenía otro significado: la autoridad competente -en este caso el Departamento de Asuntos Agrarios y Colonización- estaba sancionando oficialmente un propiedad que ya existía previamente, y ellos había probado fehacientemente:

"Los títulos presentados por los comuneros para acreditar la propiedad de sus terrenos fueron declarados auténticos por la Dirección General de Asuntos Jurídicos del Departamento de Asuntos Agrarios y Colonización..." (ibid.)

Los "títulos" que en su momento presentaron los mezcalenses y a los que refiere la Resolución, es en realidad uno solo: el llamado "Titulo Primordial", un documento supuestamente fechado en 1539 y firmado por el virrey Mendoza en que se reconoce que "... estos Poblados son Antigos de Inmemorial tiempo y moradores en este mismo suelo y angustura del Agua, de la Laguna chapalica, y de una Cierra, alta que esta al Norte". Después de la descripción de las tierras y sus linderos se otorgan en "donación y Consención de dominio y derecho de estas Tierras, en perpetua posesión y lejitima propiedad de los naturales de este Pueblo, y de toda su generación". Por ello, se insiste varias veces en que el documento es para que "...no sean despojados los Indios, posean sus tierras", dado que es una "...espesial gracia y Mersed y Venta Real y Pu- blica, para siempre jamas de aguas de tierras cerros y montes..." (Título Primordial, 1899).

Varios de los detalles del documento -nombres de personas y lugares, referencias históricas- hacen dudar de la autenticidad de la fecha de redacción. Según Castillero (2006), posiblemente fue redactado en el siglo XVII a tenor de las presiones que se sufrían por la política de composiciones de la Corona española, como tantos otros en esa época (Florescano, 1999) $)^{2}$.

La sanción oficial a la validez del Título aumentó más aún su valor simbólico dentro de la comunidad. A pesar de que nunca regresó, sigue siendo el documento base en que la comunidad de Mezcala cifra su propiedad sobre el territorio. La Resolución Presidencial de 1971 solo corrobora algo que ya se poseía "desde tiempo inmemorial", renovando con el Estado mexicano un pacto que ya se había sellado con la Corona española.

El actual territorio de la Comunidad Indígena de Mezcala está compuesto por una estrecha franja cultivable a la orilla de la laguna y un amplio macizo montañoso con escasa vocación agraria que rodea el pueblo ${ }^{3}$. Y por algo más: en el Acta del acto de "Reconocimiento y Titulación" de los bienes comunales realizado el 17 de octubre de 1974, aparece un extraño acotamiento casi al final: "los comuneros asistentes al presente acto manifestaron que dentro de los títulos primordiales se encuentra la Isla de Mezcala (Isla Indómita), terrenos que han poseído desde época inmemorial, por lo cual solicitan la pronta confirmación de la citada Isla".

De la misma forma, al final del "Acta de Deslinde y Amojonamiento Definitivo" que se llevó a cabo el 4 de septiembre de 1997, se puede leer:

"Se hace la aclaración que la comunidad tiene en posesión además de la superficie que se deslinda la Isla de Mezcala que está ubicada como a 3,500 metros enfrente del pueblo dentro del lago de Chapala".

\footnotetext{
El territorio reconocido en la Resolución Presidencial es menor al mencionado en el Título Primordial. Se perdieron las tierras fértiles y planas ubicadas al norte de la cadena montañosa que rodea el pueblo, y llegaban hasta el río Santiago. También se perdió el territorio adjudicado a Tlachichilco, que de Mezcala pasó a depender del vecino San Juan Tecomatlán.
} 
Esta insistencia muestra el valor que para los comuneros mezcalenses tiene la isla situada frente al pueblo, conocida como Isla de Mezcala o Isla del Presidio, que es considerada -junto a la Isla Chica que hay a su costado- como parte integrante de su territorio. En el Título Primordial aparece con el nombre de "Isla de Tlaltequepetque", considerada parte del territorio de Mezcala como ocurre con las aguas del lago de Chapala. Y la verdad es que no es cualquier parte del territorio: pese a su condición excéntrica, es estimada como "el corazón de la comunidad"4.

Y, sobre todo, en la Isla se desarrolló un episodio histórico en el cual los mezcalenses cifran su orgullo local y consideran un momento más de la defensa del territorio. Se trata de la "defensa de la Isla", ocurrida en los momentos más bajos de las luchas por la independencia, cuando entre 1812 y 1816 unos mil "indios de Mezcala" y otras localidades cercanas, dirigidos por un cura mestizo - Marcos Castellanos- y dos indios, uno del vecino Tlachichilco -Encarnación Rosas- y otro del mero Mezcala -José Santana- resistieron el cerco de las tropas realistas, que en los cuatro años siguientes fueron incapaces de desalojarlos de la pequeña isla y de impedir sus continuos ataques a poblaciones ribereñas. El armisticio con que se saldó el cerco conllevó la restitución de propiedades, la reconstrucción de edificios y la exención de tributos, por lo que es la base de un profundo orgullo local: "nunca nos vencieron".

Este episodio ha sido objeto de estudios históricos (Pérez Verdía, 1953; Archer, 1998; Ochoa, 1985, 2006; Castañeda, 2005) y recreaciones noveladas (Aguirre, 1966; Navarro, 1999), y mantiene cierta presencia en la historia oficial regional y estatal. Pero para los mezcalenses es fundamental: todos los años, el 25 de noviembre -fecha del armisticio- es día festivo y hay representaciones escolares del episodio. De ese momento histórico proviene un orgullo fundamental: "nunca nos vencieron". Es decir, no se apropiaron de la isla que era su territorio. Este orgullo se trasplanta hasta las actuales circunstancias: y es usada como reclamo identitario en momentos de conflicto: "...tenemos que resistir como lo hicieron nuestros antepasados" (Los coca de Mezcala siguen vivos, 2006)

\section{La inserción en el México posrevolucionario}

La Titulación de las tierras comunales de Mezcala no se hizo entonces para recuperar tierras perdidas o para lograr unas nuevas que aliviaran la presión sobre las existentes; la función de este acto legal fue la de proteger con la legislación e institucionalidad republicana el territorio que la comunidad había venido utilizando desde la Colonia como propio. Pero este acto de protección hizo cambiar las reglas internas de funcionamiento de la comunidad. Por lo que sabemos, hasta entonces todos los adultos -varones, podemos suponereran quienes elegían a las autoridades de la Comunidad, encabezados por un Presidente -como el que aparece firmando la copia del Título de 1899-. Según se desprende de los testimonios de los ancianos, en las asambleas anuales en que se elegían, se dirimían los asuntos internos y se renovaban también los Jueces de Barrio que se encargaban del orden y obras públicas en los nueve barrios de Mezcala como representantes del Delegado -que era propuesto por la comunidad-.

A partir de este reconocimiento oficial, la tierra de la comunidad de Mezcala fue manejada por una nueva institución, también denominada "Comunidad Indígena de Mezcala", pero con una nueva estructura dictada por la legislación agraria nacional. Se basa la figura de los "comuneros" como propietarios colectivos, que desde entonces se reúnen periódicamente en una Asamblea y escogen anualmente un Comisariado de Bienes Comunales dirigido por un Presidente. Esto, que pasó en muchos lugares de la República, no hubiera importado si no hubiera sido porque solo algunos de los mezcalenses pasaron a ser "comuneros" y con ello "dueños legítimos" del territorio.

Así es, cuando alrededor de 1960 se hizo el Censo Básico, por razones diversas -divisiones internas, presión de los caciques, desconfianza a la novedad-, solo 406 mezcalenses -entre la mitad y un tercio de los que 
podrían haberlo hecho- se apuntaron en el "Censo Básico". Puede ser que nos encontremos ante uno de los enfrentamientos locales que fueron tan habituales en los procesos de adjudicación y reconocimiento de tierras (Roseberry, 2004; Escalona, 2004; Baitenmann, 2007), que mientras algunos pensaron que el reconocimiento era la mejor manera de asegurar la tenencia comunal, otros pensaran que era mejor seguir como se estaba, porque pensaban que la iban a convertir en ejido y con ello dividirla. Tal vez algunos pensaron que era un buen momento para adjudicar ya a cada uno y dejarse de lo comunal; o quizá los caciques locales se dieron cuenta que esta iniciativa restringiría su poder al institucionalizar el control sobre la tierra. Cada una de estas posibilidades tiene su base y no sería extraño algún tipo de conflicto que dividiera la comunidad en ese trance.

Pero lo que sabemos es que esta situación no afectó, como sí ha ocurrido en otras comunidades (Baitenmann, 2007), a la posibilidad del uso de las tierras reconocidas. Si bien legalmente solo unos cuantos figuraron como los nuevos "propietarios" de las 3.600 hectáreas, todos los mezcalenses las siguieron usando como propias. La Comunidad reguló el uso privado en el área de la ribera y casco urbano a través de las "hijuelas" y el uso colectivo en los cerros. En este sentido, las tierras son "comunales" porque son de la comunidad, no porque se utilicen comunitariamente; es algo parecido a lo que en otros lugares llaman "ejido común" (Velásquez, 2004: 228): un uso privado por parte de todas las personas originarias y pertenecientes a la comunidad, que no solo son los "comuneros", sino todo aquel que haya nacido en Mezcala.

Así se mantuvo la Comunidad Indígena $y$ el uso de las tierras por sus habitantes y se logró una autonomía de Poncitlán en este terreno, pero desde entonces solo una parte de los mezcalenses han sido responsables de su gestión y defensa y de elegir a las autoridades agrarias. Este cambio de reglas coincidió en el tiempo con la pérdida de control de la comunidad sobre la figura del Delegado, que fue dejando de ser designado internamente, para pasar a ser competencia del Presidente electo de Poncitlán. Con ello también los Jueces de Barrio fueron perdiendo razón de ser. Estas instituciones fueron entrando en la órbita de las estructura del partido en el poder y sus diversos brazos, sobre todo campesinos: no en balde el Representante de la Liga de Comunidades Agrarias del Estado firma el Acta de Reconocimiento y Titulación de octubre de 1974; y al menos desde 1982 la Casa Comunal es un pequeño y deteriorado espacio que contrasta con el tamaño y ubicación de la Delegación.

Con esto, como en muchos lugares, las estructuras e instituciones comunitarias de Mezcala se fueron adaptando y pasando a formar parte de todo el entramado institucional creado alrededor del PRI para manejar el poder. En concreto, las autoridades agrarias entraron a formar parte de esas "instancias paralelas" al poder municipal que se basaba en la calidad de "sujeto colectivo de derecho agrario" de ejidos y comunidades con una autonomía que se manifestaba en el impuesto predial (Baitenmann, 2001: 103-107). Esto hizo que en su calidad ciudadana a través de su inserción en ese circuito de relaciones de poder, instituciones, favores, etc. -los cacicazgos regionales y estatales (Knight, 2001)-, acaban creando unos deberes y unas obligaciones que se desprenden del hecho de ser "los hijos predilectos del régimen" (Warman, 1972). En una situación en que la ciudadanía "formal", como mexicanos, es bastante deficitaria en cuanto a contenidos reales, este "ser campesino" aportaba la posibilidad de obtener acceso tanto a ciertos espacios de decisión y a satisfactores cotidianos como de conseguir servicios para la comunidad (Baitnemann, 2007). Y en concreto, para mantener la integridad del territorio comunitario de la única forma posible.

Desde esta inserción en la "cultura de Estado" (Roth et al., 2004: 192) agraria, el ser "indígena" fue en Mezcala, como en muchos otros lugares, una forma que tomó la ciudadanía agraria, una forma especial de ser campesino, que era equivalente a ser "comunero" y se encontraba en el mismo nivel que ser "ejidatario". Para las autoridades mexicanas, este término hacía relación a una forma de poseer la tierra y por tanto de relacionarse con el Estado, la sociedad y el mercado desde ese uso exclusivo del territorio. 
Mezcala, una comunidad indígena de Jalisco

Y, al revés, el estar inserto en la lógica agraria incidió en la recreación de la etnicidad, de los contenidos y formas del "ser indígena". Como dice Escalona (2004: 177), estas "redes institucionales" modelan las formas en que se vive y se reproduce la etnicidad, y en el caso de Mezcala lo hacen de una forma concreta: la de aquellas comunidades que no fueron consideradas "indígenas" en términos étnicos. En Mezcala hace mucho tiempo que dejó de hablarse el nahua, y al no contar con este u otros rasgos culturales que la "definan" o caractericen, como muchas otras comunidades en el país no han sido consideradas étnicamente diferenciadas y por tanto no fueron ni son sujetos de las políticas indigenistas del Instituto Nacional Indigenista - INI- o ahora la Comisión Nacional para el Desarrollo de los Pueblos Indígenas -CDI-. En este sentido, para el Estado mexicano, no son "indígenas", sujetos culturalmente diferenciados y socialmente "marginados" y por tanto no entraron en las redes institucionales que se definían desde una "ciudadanía étnica" menos desarrollada que la "agraria" pero también con sus propios satisfactores $^{5}$. Mezcala es un ejemplo de lo que Lameiras decía al referirse a "la persistencia multiforme de los grupos indígenas en una región que nunca había sido tocada por la política indigenista" (citado en De la Peña, 2008: 57).

Pero los mezcalenses no distinguen, y sí se consideran indígenas. Su identidad local se basa en una relación privilegiada con el territorio y la historia (Castillero, 2006; Moreno, 2008) un "estar aquí desde siempre" (Bastos, 2010). Y se consideran indígenas como una consecuencia de esta relación con el territorio - "ya estábamos cuando llegaron los españoles"-, y la propiedad comunal actual es la muestra más evidente de su calidad étnica. Por su aparición ubicua el episodio de la defensa de la Isla, el término "indio" contiene una importante carga de orgullo, que se vincula con "los antepasados", pero no excluye la conciencia de una relación de subordinación y exclusión, que se explicita en una relación con Poncitlán que responde muy bien a la idea del "proceso dominical" (Aguirre Beltrán, 1991), y renovada en los momentos en que sus vecinos les recuerdan que son "indios" de formas diferentes. Esta identidad apenas tiene un referente regional con el que se identifique con un grupo concreto (Muñoz, 2009) ${ }^{6}$. Más bien, por estar asociada a esta tierra otorgada -primero por el rey y después por el Presidente- se vive dentro de un genérico "indios mexicanos" que es una forma de insertarse en la nación (Warman, 2003a). Los símbolos de la revolución agraria -Zapata, Cárdenas- son los que pueblan el espacio y los documentos de la Casa Comunal.

Estamos entonces ante un tipo de vivencia de la etnicidad que no se basa tanto en la diferencia cultural como en la continuidad histórica y la tenencia de la tierra, y en la que no ha incidido apenas el indigenismo como sus programas "culturales". Es similar a la reportada en las comunidades nahuas del sur de Jalisco (Lameiras, 1990; De la Peña, 2006; Lucio et al., 2008), y también las del Ajusco, en el Distrito Federal (Medina, 2005 y coord. 2007; Sánchez y Martínez, 2008). En estas últimas, Medina plantea tres pilares institucionales para la recreación étnica, cuya situación en Mezcala muestra su raigambre en este tipo de colectividades, pero también la situación actual. La primera es la institucionalidad administrativa, que dejó de estar en manos de la comunidad desde que el Delegado es elegido por el Presidente Municipal de Poncitlán, normalmente entre los cuadros locales de su partido.

La segunda, la institucionalidad religiosa muestra una situación interesante. Por un lado, no existe una "carrera" ni un entramado institucional que recuerde de alguna manera al "sistema de cargos" del Ajusco, por ejemplo (Medina, 2005), ni ejerza visiblemente como esa "tercera pata" de la comunidad. Pero al mismo tiempo, las actividades religiosas y festivas han creado una red de una densidad de una profundidad y una vitalidad impre-

\footnotetext{
Evidentemente acá estoy usando el término "ciudadanía étnica" sin los contenidos que le han otorgado diversos estudiosos (ver Leyva,2007). Me estoy refiriendo a la forma en que el Estado les interpela por el hecho de ser indígenas, las redes e instituciones a través de los que lo hace y los derechos y obligaciones que ello conlleva.

6 En Mezcala solo se considera a los habitantes del vecino pueblo de San Pedro Itzican como "indígenas", pero apenas les
} incluyen en sus planteamientos identitarios. 
sionantes a través de un apretado calendario -Moreno 2008, identifica 24 fiestas en el añoen que los y las mezcalenses participan en los festejos "de barrio" y los de ámbito local, a través de "representaciones" como la "Judea en Vivo" o las "Pastorelas", los numerosos grupos de diferentes tipos de danzas -tlahualiles, huehuenches, de conquista, pacaqueros, viejitos- que congregan generaciones y orígenes diversos en momentos como las Cruces del 3 de Mayo y el día de Guadalupe o los "cargos" que vinculan a compadres, amigos vecinos y familiares alrededor de los gastos festivos. Podemos hablar de un entramado social que muestra y en el que se recrea una identidad "danzante" (Lameiras, 1990) y un sentido de pertenencia evidentes, pero sin un asidero organizativo claro.

En este contexto, la institucionalidad agraria ha sido la depositaria de la "titularidad" de la comunidad: los comuneros han sido los encargados de la interlocución con el Estado, de la que ha dependido buen parte de la calidad de indígenas. Ha conseguido cumplir su papel de "los guardianes del territorio" en medio de un entramado político cambiante y una pérdida progresiva de membresía. Pero los comuneros fueron envejeciendo y no nombraron herederos, pues pensaban que los jóvenes iban a acabar vendiendo las tierras.

\section{Mezcala ante el Estado neoliberal y la globa- lización}

Con el cambio de siglo, fueron llegando a Mezcala los efectos de las transformaciones que venían gestándose en el mundo y en el Estado mexicano en los últimos tiempos. En las últimas décadas, la población y el territorio de Mezcala han ido entrando en las dinámicas de la globalización a través de formas muy variadas. Por un lado, los mezcalenses fueron saliendo a Estados Unidos como tantos otros lugares del occidente de México a partir del Programa Bracero en los años cuarenta del siglo XX y desde entonces no han parado. Las huellas de "El Norte" están presentes en todas partes, más allá de la dependencia de las remesas: las obras del Club Mezcala; la presencia de "los Hermanos Ausentes" en la
Feria Titular en agosto; los jóvenes con la indumentaria popular latina organizados en gangas. Esta relación con los Estados Unidos es la muestra más evidente del proceso de dispersión poblacional que se ha dado en Mezcala, que llega a ciudades de la frontera norte, pero sobre todo a Guadalajara y todo el corredor de El Salto.

La cercanía con Guadalajara promueve otro proceso que tiene que ver con la relativización de las fronteras entre lo urbano y lo rural (Arias, 2009), que se aprecia en procesos como la combinación residencial entre el pueblo y el área metropolitana, el complemento de la actividad agrícola con los empleos urbanos, la dedicación de parte del suelo a actividades periurbanas, el empleo de jóvenes mezcalenses en las maquilas de Guadalajara, etc. La dinámica de urbanización de localidades rurales periféricas afecta a Mezcala de forma especial, pues se combina con la presión del capital inmobiliario de la ribera de Chapala, que ya no ha dejado prácticamente espacio en la zona noroccidental ${ }^{7}$. A través de esta presión, los mezcalenses se vinculan al turismo, que empieza a estar presente en el paisaje cotidiano del pueblo a través de algunos negocios, los paseos a la Isla, y los carteles cada vez más presentes de propaganda institucional.

Y sobre todo, está presente en combinación con una nueva ola de presión sobre el territorio comunitario, con fines inmobiliarios, que se inauguró en 1999 con la "invasión" por Guillermo Ibarra, un empresario tapatío del Cerro del Pandillo, donde bajo excusa de un programa de reforestación y usando un "prestanombres" local construyó una mansión en pleno territorio comunitario. Casi al mismo tiempo en que la comunidad reaccionaba y emprendía un juicio agrario contra el invasor, en 2002 se inauguraba la carretera que unía la comunidad con Chapala y había sido postergada por más de 50 años. En vez de seguir el camino de terracería existente, se abrió a media altura del cerro, para lograr una "carretera panorámica" con vista al lago. En 2005 "llegó PROCEDE", como recuerdan los comuneros, y en Asamblea se decidió que no se aceptaría

En el área entre los poblados de Chapala y Jocotepec, sobre todo alrededor de Ajijic, se ha instalado desde mediados del siglo XX una importante colonia de jubilados norteamericanos, llegando a saturar totalmente el espacio disponible. 
firmar la desincorporación de las tierras ${ }^{8}$. Pese a ello, el Plan de Ordenamiento Territorial para Mezcala que preparó la Presidencia de Poncitlán sí incluía partes del territorio dedicadas a "zonas turístico-hoteleras de densidad media" y otras con el eufemismo de "zonas habitacionales de densidad media" (Gobierno Municipal de Poncitlán, 2006.

Ante esto, se fue generando una sensación de acoso entre los comuneros y demás mezcalenses, que se puede resumir en una de las frases más escuchadas: "No queremos acabar como los de Ajijic, sin tierras y trabajando para los extranjeros y tapatíos", y que se materializó en respuestas colectivas concretas, como la que cuenta un comunero:

"... en los años de 1990, estaban circulando varias hectáreas en la parte de El Comal. El [Presidente] de Bienes Comunales, los comuneros y población en general de Mezcala, nomás nos fuimos todos a cortar los alambres con los que habían cercado nuestras tierras. Querían fraccionar $\mathrm{El} \mathrm{Co-}$ mal,... fueron varios días los que se fue para limpiar todo. Ya nomás les dejamos todos sus alambres y postes, pa' que no digan que estábamos robando".

Todos estos hechos parecen mostrar el destino asignado por las diferentes esferas de Gobierno a esta localidad como parte de la ribera de Chapala y bajo los efectos de los cambios en los artículos 4 y 27 constitucionales. Mezcala ha dejado de ser para el Estado una comunidad campesina y se va convirtiendo en un espacio que debe insertarse a la economía del turismo que domina la región, como proveedora de servicios y espacio de construcción. El desmontaje del Estado corporativo agrarista abre nuevas "oportunidades" de inserción económica para las comunidades antes agrarias, una nueva relación que se buscó cristalizar a través del PROCEDE. Se pretendía que ya no fueran un sector bajo especial protección del aparato estatal, sino unos ciudadanos que se insertaran al mercado como propietarios de unas tierras que pueden ser mejor trabajadas por otros, que a su vez empujarían a una inserción más competitiva de México en la economía global (Zendejas y De Vries, eds., 1995; Warman, 2003b). A partir de ese momento se han ido desmontando las estructuras del Estado posrevolucionario. En Mezcala, este desmontaje ha ido de la mano de las políticas estatales y municipales para promocionar las actividades turísticas e inmobiliarias, que han provocado la reacción de los mezcalenses organizados.

El evento que más claramente ha mostrado esta intención de convertir a Mezcala en un destino turístico abierto al mercado inmobiliario, ha sido la restauración de los edificios de la Isla, que se iniciaron en 2006 a raíz del Bicentenario de la indepedencia que entonces se acercaba. Tras unos estudios arqueológicos e históricos -que parecieron ser insuficientesen 2007 empezaron las obras físicas llevadas por un equipo en que el INAH avalaba y daba el soporte técnico, la Secretaría de Cultura aportaba el financiamiento y la Presidencia Municipal de Poncitlán ejecutaba la obra. A partir de ese momento, las obras han ido avanzando a golpe de presupuesto y temporadas secas, pero con la oposición creciente de unos comuneros renovados y activos.

Desde que empezó este proceso, la Asamblea de Comuneros se quejó de que las instancias de los tres niveles de gobierno no le estaban teniendo en cuenta como autoridades responsables de una tierra que de propiedad comunal. Denunciaban la forma en que se estaban llevando a cabo las obras, que demostraba poco respeto por la historia de los insurgentes de Mezcala y por la cantidad y calidad de los restos que pudieran haber en un lugar como la Isla. Así, el hecho de que se reconstruyera el presidio edificado después de la defensa, muestra claramente para los comuneros cómo el objetivo de toda la obra no es exaltar aquel episodio histórico en el contexto del Bicentenario, sino activar una atracción turística que refuerce el papel de Mezcala en la zona. Y ante esto, los comuneros denuncian que ese modelo de turismo que se les quiere

$8 \quad$ El Programa de Certificación de Derechos Ejidales y Titulación de Solares Urbanos, PROCEDE, surgió de los cambios en el Artículo 27 constitucional. Busca regularizar la tenencia de tierras ejidalesy comunales y, sobre todo, permite su posterior demembramiento (Zendejas y De Vries, 1998). En este momento Mezcala es la única comunidad agraria de la ribera de Chapala y el municipio de Poncitlán que no entró al PROCEDE. Vecinos como San Juan Tecomatlán, Tlachichilco o San Pedro Itzicán sí lo hicieron, y normalmente al principio del proceso, en los 90. 
imponer, en el que de nuevo se repite la inserción que, como pueblos indígenas, les han obligado durante siglos.

\section{La recreación comunitaria como Pueblo Coca}

Este enfrentamiento se ha dado en forma paralela y ha reforzado todo un proceso de renovación interna que se ha dado en la comunidad indígena de Mezcala y que se pueden entender como el proceso de recreación y adaptación de la lógica comunitaria al contexto que podríamos definir como global neoliberal multicultural.

Cuando los fenómenos descritos se fueron mostrando como amenazas evidentes a la integridad territorial que había sido la razón de ser del Comisariado, los comuneros empezaron a ver la necesidad de renovarse institucional y generacionalmente. Para ello, se aliaron con un grupo de jóvenes mezcalenses que desde inicios de siglo venían trabajando como "Colectivo Mezcala" en las redes zapatistas de Guadalajara, alrededor de todo lo que supuso la "6a Declaración de la Selva Lacandona" y más tarde "La Otra Campaña". Desde estos espacios y basándose en la evidencia etnohistórica (Baus, 1982), en este Colectivo se desarrolló la propuesta de Mezcala como una comunidad perteneciente al "Pueblo Coca" (Moreno, 2008; Moreno, Jacobo y Godoy, 2006). Cuando se planteó en Jalisco la aprobación de una Ley Indígena Estatal que sirviera de soporte a la Ley planteada por Fox en 2001 (Hernández, Paz y Sierra, 2004), Mezcala no fue considerada como "pueblo indígena" de Jalisco. Esto reforzó la alianza con los sectores de oposición que alrededor del CNI se habían negado a dar por buena esta ley ${ }^{9}$.

"Es paradójico que la propuesta estatal de ley indígena de Jalisco niegue a los coca de Mezcala como pueblo indígena por "no cumplir" los "requisitos" que el actual gobierno pretende imponer para certificarlos, cuando que el mismo gobierno es el culpable de su erosión cultural. Su no re- conocimiento es otro ataque a los pueblos. (Los coca de Mezcala siguen vivos, 2006)

De hecho, tras el paso de la caravana de "La Otra Campaña" por el cercano municipio de El Salto y la participación en actividades del Congreso Nacional Indígena - $\mathrm{CNI}$-, el Colectivo logró que se realizara en Mezcala en noviembre de 2006 el "Foro Nacional de Defensa de la Madre Tierra y la Autonomía Indígena", que convocó a representantes de grupos variados y contó con la presencia de dos comandantes del EZLN expresamente llegadas de Chiapas. Fue el Comisariado el que, como miembro del CNI, organizó la actividad. Con ello se reforzó la vinculación con los jóvenes del Colectivo, y les sirvió para conocer comunidades que, en situaciones similares, habían procedido a una transformación.

Así empezó el proceso de renovación interna de la Comunidad, que movilizó a más de 200 personas semanalmente durante un par de años, y se ralentizó con el cambio de autoridades comunitarias de agosto de 2008, cuando entró en una fase de conflicto interno y externo de la que apenas se sale a finales de 2009. Los ejes de este proceso han sido las actividades de ampliación de la base social, la redacción de un Estatuto Comunitario y la renovación de la defensa del territorio desde nuevos foros y espacios ${ }^{10}$.

Cuando empezó esta dinámica, solo quedaban ochenta comuneros vivos, de los que la mitad hacía mucho que no residían en el pueblo. Como consecuencia, unos cuarenta comuneros acudían regularmente a las asambleas y actividades del Comisariado. Esto no solo implicaba una merma en la representatividad, sino una seria dificultad para la capacidad de un trabajo que, sin embargo, llevaban con entereza. Por ello, tras la reunión del Foro de Defensa de la Tierra, la misma Comunidad buscó cubrir la brecha generacional abierta y aprovechar para ampliar la pertenencia más allá de sus miembros originales y sucesores, para subsanar la situación creada con el Censo Básico. La renovación del Censo se hizo a

\footnotetext{
9 Siguiendo la lógica del periodo indigenista, los "pueblos indígenas" de Jalisco son, según la Ley Indígena, el Pueblo Wixaritari y el Pueblo Nahua, además de los miembros de migrantes de las ciudades (Ley sobre los Derechos y el Desarrollo de los Pueblos y las Comunidades Indígenas del Estado de Jalisco", 2006).

10 El Estatuto se trabajó durante 2007 y 2008 , y finalmente fue aprobado por la Asamblea en junio de 2009 y ratificado por el Tribunal Agrario, posteriormente.
} 
través de "juicios de herencia", por los que se buscaba recuperar a los descendientes de 406 censados originarios. Al mismo tiempo, se abrió un proceso de "ampliación" a gente que quisiera pertenecer a la Comunidad. Aunque las dificultades legales no han permitido aún completar estos procesos, desde 2007, los "nuevos comuneros" son un grupo de unas cien personas que realizan diversas actividades en la Comunidad y una parte acude regularmente a las Asambleas, aunque no tengan aún derecho a voto.

Esto implica algo más que un relevo generacional, pues los hombres y mujeres que se han sumado de hecho ya a las actividades de la Comunidad suponen una ampliación importante de la gama de ocupaciones y actividades, que superan con mucha la concepción de la comunidad solo como "agraria". Algunos de los jóvenes estudiantes y profesionistas, los albañiles, obreros y técnicos diversos, los migrantes y lancheros mantienen una actividad campesina al cultivar chayote $u$ otros productos, pero no viven de eso, y han ampliado con ello los temas de preocupación de la Asamblea. Lo mismo ocurre con las opciones ideológicas. Si en el pasado la pertenecía al partido oficial era la única forma de participación política, en la actualidad, los miembros de la Comunidad responden a la variedad de partidos y opciones presentes en Jalisco -desde el PAN al zapatismo, pasando por el PRI, PVEM o PRD-, que ha sido resuelta con el acuerdo de dejarla fuera de las actividades de la Comunidad ${ }^{11}$.

Esta ampliación generacional, además de ser habitual en diversos momentos en las comunidades agrarias del país (Dietz, 1999, Martin, 2002; Bofill, 2002; Gil, 2006; Garibay, 2002;), es un primer paso hacia una nueva comprensión de la idea de la Comunidad, que de lo agrario -formada por los propietarios de la tierra- lleva a lo indígena, todos los integrantes del núcleo histórico que es Mezcala. La transición es lenta -la mayoría de los "nuevos comuneros" pertenece a familias de comuneros censados- porque la dependencia de la legitimidad agraria y los sentidos de perte- nencia que otorga son fuertes, pero incluso en el Estatuto aparece ya esta concepción:

ARTICULO 13. - La Asamblea General se integra para efectos agrarios con la participación de todos los comuneros en pleno goce y ejercicio de sus derechos, y para las demás cuestiones en general por aquellos originarios legítimos de la Comunidad Indígena de Mezcala, que respeten los principios de este estatuto". (Estatuto..., 2008: 8).

Incluso, de una forma aún tímida, se hace frente al hecho de la dispersión espacial de la comunidad mezcalteca. No estamos frente a una renovación institucional que permita hablar de una "comunidad transnacional" (Besserer, 2002; Gil, 2006), y de hecho el texto es aún conservador en cuanto a la definición de los sujetos a la "ciudadanía comunitaria", como aquellos nacidos en el territorio de Mezcala. Pero se reconoce institucionalmente al Club Mezcala y la dificultad de cumplir los requisitos por la residencia fuera del pueblo.

Este nuevo Estatuto es la columna vertebral de la reconstitución comunitaria alrededor de la Asamblea de Comuneros, pues pretende superar lo agrario para convertirse en la "constitución" que rija la ciudadanía comunitaria de los mezcalenses como parte de un Pueblo Indígena, un "Pueblo Coca de Mezcala" que renueva su "Gobierno Tradicional" para mantener su autonomía. Este Estatuto es quizá la mejor muestra de la nueva propuesta de comunidad que ya no se entiende como una instancia agraria de unos "indígenas mexicanos", sino como parte de un Pueblo Indígena con derechos históricos sobre el territorio. Ante la negativa de reconocimiento oficial y con la inserción en las redes zapatistas, se refuerzan las argumentaciones sobre su uso ancestral -tan presente en la lógica local mezcalteca- que conllevan a un ejercicio del autogobierno y la búsqueda de la autonomía de Pueblo originario. Así, el Estatuto reclama su legitimidad del Título Primordial, de la Constitución y las leyes agrarias mexicanas

Es cierto que, a diferencia de lo que es normal en esta comunidades agrarias (Muñoz, 2009, por ejemplo), en las Asambleas de Mezcala se junta gente que fuera realiza actividades partidistas -como se vio claramente en la campaña electoral de mediados de 2009- pero que en su interior no lo manifiesta y trabaja conjuntamente; y que las divisiones internas que pueda haber entre comuneros -o con otros sectores locales- no corresponden con las de los partidos. 
-que los neozapatistas reivindican como parte de la herencia revolucionaria- y del Convenio 169 de la OIT, que les permite la calidad de pueblo y del que se destaca el derecho al usos del territorio.

Esta renovación de las bases ideológicas de la comunidad se manifiesta en la formulación de la idea de un "Gobierno Tradicional de la Comunidad" cuyo núcleo son las instituciones agrarias -Asamblea General de Comuneros, Comisariado de Bienes Comunales, Consejo de Vigilancia- pero que incluye otras instancias comunitarias existentes -Jueces de Barrio y Delegado Municipal- y otras nuevas - Consejo de Primeros Comuneros, Comisión de Seguridad Comunal, Capitanía de Puerto de la Comunidad de Mezcala y Comisión de transparencia y presentación. Según el Estatuto, son aquellos "órganos y autoridades" que "de acuerdo a los usos y costumbre propios integran el Gobierno Tradicional de la Comunidad" (Estatuto, 2008: 7).

Así, a partir de las estructuras vigentes, se busca ampliar las bases de representación y gobierno desde una nueva legitimidad indígena basada en el "gobierno tradicional" y los "usos y costumbres". Suponen nuevas formas de entender y nombrar la realidad comunal y su existencia es la que da derecho al autogobierno y capacidad de decisión sobre su territorio -y la Isla en concreto- según las nuevas formas de entender los derechos de los pueblos indígenas.

Este Estatuto surge en un contexto concreto de defensa de la integridad territorial ante los embates que sufre. Por eso no ha de extrañar que bastantes de sus artículos se dediquen a la defensa de esta integridad por diversas vías -incluso la expulsión de los "prestanombres"- y que, en ella, la Isla ocupe un lugar importante ${ }^{12}$. Y, de hecho, bastante del proceso de renovación comunitaria ha girado alrededor de las actividades ligadas con la defensa del territorio, que ha mantenido el espíritu de lucha entre los comuneros -censados y nuevos-, ha supuesto una dinámica de renovación de la pertenencia comunitaria y ha sido expuesto en foros y actividades. Los enfrentamientos con el INAH, la Secretaría de Cultura y la Municipalidad de Poncitlán son los que han sido más conocidos y han generado más dinámicas internas y externas. Ante esta nueva amenaza al territorio, se reforzó el papel del Comisariado de Bienes Comunales, como núcleo desde el que se ha venido haciendo una oposición a unas obras que se convirtieron en una cuestión política de alcance estatal y federal de mano de las diferentes redes con las que se relaciona el Colectivo y ahora la Comunidad: no solo el CNI, sino los Afectados Ambientales, los colectivos anarkopunks, los espacios académicos. En estos espacios y en las actividades locales, el discurso como Pueblo Indígena se utiliza para reforzar los argumentos históricos sobre los que está construida la identidad mezcalense (Bastos, 2010), que toma así una nueva dimensión más allá de lo local y en que empiezan a aparecer elementos relacionados con "la cultura"13.

"La comunidad de Mezcala, en la ribera del lago de Chapala, es un bastión de resistencia indígena que tuvo su momento cumbre en lucha por la independencia de México al defender su isla contra el Ejército Realista" (Los coca de Mezcala siguen vivos, 2006).

"Por qué lucharon los insurgentes? Lucharon por el respeto a nuestras tierras, gobierno y cultura, buscaban la libertad para

12 ARTÍCULO 148.- Las tierras de la Comunidad gozan de la protección especial que les otorgan la Constitución Mexicana y el Convenio Ciento Sesenta y Nueve de la Organización Internacional del Trabajo "Sobre pueblos indígenas y tribales en países independientes" así como la Ley Agraria. ...No podrán existir enajenaciones, fideicomisos, concesiones, embargos, despojos, etc. dentro del territorio de la comunidad" (ibíd.: 36). ARTícULO 161.- Cualquier persona ajena a la comunidad que pretenda poseer terrenos de la comunidad se le reconocerá como invasor" (ibíd.: 39). ARTíCULO 183.- La isla, por su importancia, pues es el corazón del territorio de nuestra comunidad, seguirá siendo custodiada por la misma comunidad, por lo que nadie puede crear posesiones" (ibíd.: 43).

13 La historia suele ser un elemento importante de justificación de las demandas y discursos, y más en espacios indígenas; dando lugar a la construcción de versiones enfrentadas e incluso contradictorias (Velásquez, 2004; Gómez Carpinteiro, 2004), pero en Mezcala juega un papel importante en la identidad local -posiblemente ante la ausencia de otros elementos distintivos- (Bastos, 2010) y además es una base importante de una memoria local que da mucha importancia a las fuentes escritas (Óscar Muñoz, 2009 "Informe-ensayo de la comunidad indígena de Mezcala. Lectura del manejo de la Historia que hacen sus habitantes"). 
el pueblo" (El Pueblo Coca de Mezcala. Una Historia de Lucha, 2008).

"Nuestra historia, nuestros abuelos nos han enseñado a defender lo nuestro, así que de la misma manera que ellos empezaron a anunciar su gran proyecto de turismo para el rico sobre el pobre, sobre nuestro pueblo y su historia, nosotros presentamos el sentir de nuestra comunidad" (Declaratoria de Mezcala, 2008).

Más allá del discurso, la lucha por la integridad del territorio comunitario llevó a los comuneros -censados y nuevos- a enfrentarse a intereses concretos. $Y$ no es solo el proyecto de inserción económica que defendía la Presidencia Municipal de Poncitlán y al que se sumaron la Secretaría de Cultura y el INAH. Además, había intereses particulares como el de Ibarra que se jugaba en el juicio del Pandillo; además de aquellos de los mezcalenses insertos en estos procesos. La oposición a estos actores fue ganando fuerza mientras se consolidaba el proceso de renovación y ampliación de la base social de la Comunidad. Todo esto suponía un nuevo proyecto de comunidad, diferente en parte al que se puso en marcha a mediados del siglo XX. De nuevo, como medio siglo antes, dos versiones estaban en pugna.

Y así, todo se paralizó tras las elecciones para las autoridades comunitarias de agosto de 2008 , en que venció una planilla compuesta por gente que no había participado en el proceso previo y que apenas conocía la mecánica del Comisariado. A finales de ese año, los comuneros se quejaron de que los procesos judiciales de renovación y de recuperación de las tierras no avanzaban, que las autoridades no convocaban a la Asamblea y en cambio negociaban con la Municipalidad sobre el futuro de las obras de la Isla. Asumiendo entonces que trabajan para defender intereses ajenos a la comunidad, en marzo de 2009, la Asamblea les desconoció, pero ellos siguieron con el apoyo de la Municipalidad y el Delegado. Comenzó una época de "doble directiva" en que ambas decían manejar la legitimidad y legalidad: las autoridades depuestas, las que provenían de la Municipalidad; y las recién electas, de las instancias agrarias y de la Asamblea comunitaria -elemento clave en la dinámica local.
En octubre de 2009 se produjo un allanamiento a la Casa Comunal por parte de los depuestos, acompañados de Ibarra y protegidos por la Policía Municipal, a lo que siguió un plantón por parte de los comuneros que duró un mes y sirvió para reforzar su posición entre los mezcalenses. Esta demostración de fuerza sirvió para terminar con la alianza entre el INAH y la SCJ con la Municipalidad Poncitlán, pues el recién elegido Presidente Municipal decidió dejar la táctica de su predecesor -pese a ser también del PRD- y desde antes de tomar posesión inició un acercamiento con los comuneros que para mediados de 2010 se manifiesta en una serie de obras y proyectos conjuntos. $Y$ en un acuerdo sobre el manejo de la Isla y las obras al que se sumó también la SCJ.

\section{Continuidad histórica, renovación y comunalismo indígena}

Mezcala, como otras comunidades indígenas, se halla en un momento de renovación y para ello apela a su profunda base histórica, que es vista ahora desde nuevas perspectivas. Pero este proyecto no sería posible sin la existencia de una serie de prácticas y comportamientos que son los que nos permiten hablar de Mezcala como una comunidad. La identidad local compartida y su raigambre en el territorio; la organización local a base de barrios; las prácticas sociales como las danzas, fiestas y otros rituales en que todo el pueblo se suma; las instituciones agrarias. Todas ellas serían las muestras del "comportamiento comunitario" (Zárate, 2004: 63) que se ha ido formando en el tiempo y cuyas estructuras actuales vienen del agrarismo posrevolucionario sin indigenismo, en un contexto de dispersión, metropolización y diversificación.

Estamos pues ante un espacio social que podemos considerar como una comunidad por su historia e institucionalidad local, pero que lejos de responder a la imagen de una localidad rural, aislada o "tradicional", está totalmente cruzada por dinámicas propias de la globalización -la migración, las políticas neoliberales, el turismo, la metropolización, la revitalización étnica- que impulsan hacia una renovación como tal comunidad, más que a su desaparición. 
Para entender este momento y las dinámicas que se dan en él, es útil la diferenciación entre los comportamientos comunitarios, como "prácticas culturales conformadas históricamente" y el "comunalismo como ideología", que "exalta el ideal de la comunidad y la vida comunitaria" y puede convertirse en el motor que mantenga vivos, de hecho, esos comportamientos históricamente creados, renovándolos de acuerdo al nuevo contexto (Zárate 2005: 63-65).

Lo que está ocurriendo en Mezcala es lo que se puede entender como "recomunalización": más allá de una dicotomía entre la desaparición y el "regreso" a una situación ideal que a saber sí existió, se trata de un proceso por el cual se está renovando y a la vez transformando la calidad comunitaria de los comportamientos sociales de los mezcalenses. A pesar de los presagios más catastróficos sobre los efectos de la migración o la salarización en la ciudad en "las costumbres", la participación masiva en los rituales y danzas -con una gran presencia de jóvenes-, la renovación institucional y la participación de los migrantes muestran una vitalidad comunal renovada. Pero el futuro no va a ser algo parecido a lo que hubo, sino un tipo de comportamiento social adaptado al contexto de globalización -turismo, migración, derechos indígenas- y políticas neoliberales.

Acá es donde entra el "comunalismo". Cuando las instituciones y la legitimidad del Estado corporativo se derrumban y ser una comunidad indígena en términos agrarios ya no es garantía para mantener la integridad del territorio -como lo fue en las cinco últimas décadas para los mezcalenses-, empieza a ser más útil ser considerado como indígena desde la figura de "Pueblo" y todo lo que ello conlleva. En palabras de Roth et al. (2004: 208), cuando "se eliminaron las garantías del Estado para la continuidad de las comunidades y los comuneros", se retomó el discurso étnico que se había ido construyendo a otro nivel. Con ello se fue eliminando "la separación cultural entre comunalismo popular y la etnicidad" que dejó de ser un recurso en la "cultura de Estado"14.
De esta manera, el nuevo discurso etnizado de la comunidad enlaza así con la legitimidad internacional de los derechos indígenas que permite añadir nuevas facetas a los reclamos -como el de autonomía- insertos en redes más amplias de reivindicaciones indígenas y antineoliberales. Con ello se está dando una reinvención de la comunidad como forma de insertarse a la globalización.

Pero ahora, para que la comunidad se pueda seguir manteniendo, es necesario "reimaginar la comunidad" (Velásquez, 2004: 221), una renovación, lo que significa ser mezcalense, actualizar los contenidos históricos sin perder su capacidad de identificación. Como también dice Zárate (2004: 71), para que este tipo de procesos sea exitoso, depende al menos de dos procesos. Uno es el establecimiento de una versión de la comunidad, un discurso comunalista, que logre consenso entre los diferentes sectores que la forman. En este caso el discurso que se está construyendo es el asociado al Pueblo Coca, que propone una lectura del recorrido histórico de la comunidad desde unos orígenes ancestrales que hasta ahora no tenían importancia -pero son importantes en la legitimidad poscolonial-.

Esta renovación del discurso es vista como un paso más dentro de una forma histórica de mantener el control sobre el territorio: el Título Primordial supuso aceptar las reglas de la Colonia -que el rey les había "otorgado" algo que ya era suyo-; la defensa de la Isla se hizo para mantener ese control -y sirvió para renovarlo por lo menos un siglo más-. Después de la Revolución, fue necesario solicitar el "reconocimiento presidencial", asumirse como parte de los "hijos predilectos", diluyéndose a cambio parte de su ser indígena. Pero si ahora el Estado ex agrarista ya no es capaz de asegurar el control sobre el territorio, quizá haya que buscar la seguridad en la legitimidad como Pueblo Indígena.

Esto implicaría la novedad de que la seguridad del territorio ya no se busca a través de una "concesión" del Estado, sino reclamándole que cambie su actuar en relación a ellos. Por ejemplo, reconociéndole como indígena

14 Al utilizar el discurso étnico desde este "comunalismo popular", se crea de hecho una alternativa a las políticas oficiales de la diversidad (Hérnandez et al. 2004), que "no reconocen este espacio" (Roth, 2004: 208) de forma legal como sujeto de derecho. 
como no se ha hecho antes y aunque no se cumplan los "requisitos culturales" e institucionales. De ahí lo novedoso de la propuesta del Pueblo Coca: no hay antecedentes de relación con el Estado desde esa etiqueta, no está "contaminada", no forma parte de la "cultura de Estado" de los jaliscienses.

Pero, por otro lado, estos contenidos poscoloniales -Pueblo Indígena, ser "Coca"son los que más cuestan a los mezcalenses, en parte por su novedad (Bastos, 2010), su ausencia en la "cultura política" local y de los contenidos aprendidos de identidad. En cambio, lo que sería la especificidad mexicana actual de esta lógica poscolonial -la versión zapatista-, no cuesta tanto a los mezcalenses, pues reúne elementos de la izquierda mexicana que sí les son conocidos.

El reto es lograr que la identidad como Pueblo Coca sea asumida por los mezcalenses como propio y garantice la cohesión alrededor de la idea de la comunidad como espacio social legítimo. Pero lo que les llama la atención y les cuesta incorporar a los mezcalenses es la calidad de "Pueblo" y el apelativo de "Cocas", que es precisamente donde se manifiestan los elementos que podríamos considerar multiculturales: el reclamo de ancestralidad como pueblos originarios y la cultura como elementos identificador. Sin embargo, la versión zapatista en boga en Mezcala apone el énfasis en la autonomía y oposición al Estado, y no tanto en los derechos culturales. Por su origen de izquierda, se relaciona el ser indígena con el ser pobre y con la violencia y el despojo histórico que se actualizan en el contexto de globalización neoliberal. Los términos de resistencia al poder en que se plantean, de una forma muy unida al "ser mexicano", hacen que esta versión suene conocida para los mezcalenses por su pasado agrarista. Y tampoco les suena mal el reclamo a una "autonomía" que vienen reclamando históricamente del Municipio de Poncitlán. De esta forma, los contenidos de la nueva propuesta van pasando "selectivamente" (Nugent y Alonso, 2002) a la identidad mezcalense.
Pero además, para que el proceso de recomunalización avance, se debe mostrar su funcionalidad. En Mezcala no hay un recurso económico como el forestal (Garibay, 2008; Bofill, 2002) que el Comisariado pueda manejar y ser la razón de ser de esa renovación y, sobre todo, de la legitimidad local de la estructura agraria. Hay en marcha planes de cooperativas, de empresas comunitarias ligadas a la nueva Comunidad, pero hace falta una razón para que los comuneros convenzan al resto de sus vecinos de la utilidad y conveniencia de mantener el carácter común y excluyente de su territorio. Es necesario demostrar que en estos momentos de globalización, la tenencia comunitaria de la tierra puede ser mas útil y beneficiosa que la entrada a ese "progreso" que propone el Estado, y que en este caso está asociado directamente a la gestión de turismo. Por eso, la nueva "batalla por la Isla" es crucial, pues en ella se va a dirimir la posibilidad de una gestión comunitaria ajena a los cánones neoliberales que maneja el INAH ${ }^{15}$.

La apuesta que está detrás es lo que Garibay (2008: 16) llama "la revolución comunalista", mostrar que la tenencia comunitaria puede aportar una base para que todos los mezcalenses mejoren sus condiciones de vida aprovechando comunitariamente un recurso nuevo, en contra de lo que él lama "el modelo campesino liberal capitalista" representado en este caso por la oferta de PROCEDE. En el contexto actual, la tierra ya no es solo un recurso agrícola, el territorio de Mezcala ha adquirido un valor mayor como "paisaje", "naturaleza", y tiene otros valores anexos como "historia" y "cultura". Y eso se puede gestionar de una manera acorde a los intereses de los mezcalenses y sin que signifique atentar contra la historia y la identidad que han permitido llegar a esta situación. Pero se puede ir más allá del turismo y buscar insertarse en la globalización como Indígenas Cocas de una forma no "deficitaria", como ha sido históricamente. Es decir, darle la vuelta a los contenidos históricos de la condición indígena, a partir de dar nuevo sentido a la construcción histórica de la comunidad, dentro un contexto ahora globalizadas. 


\section{Bibliografia}

AGUIRRE BELTRÁN, G. (1991), Regiones de Refugio. El desarrollo de la comunidad y el proceso dominical en Mestizoamérica. Obra Antropológica, IX (1 $1^{\text {a }}$ ed., 1967). Fondo de Cultura Económica, México.

AGUIRRE, M. J. (1966), Mezcala, la isla indómita. Ediciones Estudiante, S.A., Guadalajara.

APPADURAI, A. (2001), "Dislocación y diferencia en la economía cultural global", en La modernidad desbordada. Dimensiones culturales de la globalización, Eds. Trilce / FCE, México.

ARCHER, CH. I. (1998), "The Indian Insurgents of Mezcala Island on the Lake Chapala Front 1812-1816", en Native Resisitance and the Pax Colonial in New Spain, Susan Schroerder, Ed. University of Nebraska.

ARIAS, P. (2009), Del arraigo a la diáspora: dilemas de la familia rural. Porrúa / Universidad de Guadalajara, México.

WARMAN A. (1972), Los Campesinos: hijos predilectos del Régimen. Nuestro Tiempo, México.

(2003A), Los indios mexicanos en el umbral del milenio. Fondo de Cultura Económica, México.

(2003B) "La reforma agraria mexicana: una visión de largo plazo", FAO Document Repository, versión pdf http://www.fao.org/DOCREP/006/J0415T/j0415t09.htm

BAITENMANN, H. (2001), "Las paradojas de las conquistas revolucionarias: municipio y reforma agraria en el México contemporáneo", Gestión y Política Pública, vol. X, num. 1, primer semestre.

(2007) "REFORMA agraria y ciudadanía en México", en Paisajes mexicanos de la reforma agraria. Homenaje a William Roseberry. Francisco Javier Gómez Carpinteiro, editor. El Colegio de Michoacán / Benemérita Universidad de Puebla / CONACYT, Zamora.

BASTOS, S. (2000), Cultura, pobreza y diferencia étnica en ciudad de Guatemala, Tesis, Doctorado en Ciencias Sociales CIESAS-UdeG, Guadalajara.

(2007) "LA construcción de la identidad Maya como un proceso político", en S. Bastos y A.Cumes (coords.) Mayanización y vida coti- diana. La ideología multicultural en la sociedad guatemalteca. Volumen 1: Introducción y análisis generales. FLACSO Guatemala / CIRMA / Cholsamaj, Guatemala.

(2010) "MEZCALA ante la globalización: renovando los amarres de la historia", en Migración, procesos productivos, identidad y estigmas sociales, J. Cajas, coord. Juan Pablos Editor / Universidad Autónoma del Estado de Morelos, México.

BASTOS, S. y MUÑOZ, O. (2010), "Los insurgentes de Mezcala' (1812-1816). Conflictos internos y externos ante la celebración del Bicentenario", Cuadernos de Marte $\mathrm{n}^{\circ}{ }^{1}$. Instituto de Investigaciones Nino Germani de la Universidad de Buenos Aires, Argentina.

BAUS DE CZITROMN, C. (1982), Tecuexes y Cocas. Dos grupos de la región Jalisco en el siglo $X V I$. Colección científica $\mathrm{n}^{\circ} 112$. Instituto Nacional de Antropología e Historia, México.

BESSERER, F. (2002), Topografías Transnacionales. Una geografía para el estudio de la vida transnacional. Universidad Autónoma Metropolitana. Unidad Iztapalapa/Plaza y Valdés, México.

BOFILL, S. (2002), "Negociando el interés común: Poder, conflicto y reciprocidad, en San Juan Nuevo, Michoacán", Relaciones № 89, invierno 2002.

CAMUS, M., ed. (2007), Comunidades en movimiento. La migración internacional en el norte de Huehuetenango. INCEDES / PCS, Guatemala.

CASTAÑEDA, C. (2005), Los pueblos de la Ribera del Lago de Chapala y la isla de Mezcala durante la independencia (1812-1816), Gobierno del Estado de Jalisco, Guadalajara.

CASTILLERO, R.M. (2006), Mezcala: expresión de un pueblo indígena en el periodo colonial. Vicisitudes y fortaleza. Universidad de Guadalajara, Guadalajara.

DE LA PEÑA. G. (1998), "Etnicidad. Ciudadanía y cambio agrario. Apuntes comparativos sobre tres países latinoamericanos", en Las disputas del México Rural, S. Zendejas y P. de Vries, eds. El Colegio de Michoacán, Zamora.

(2006) CULTURAS indígenas de Jalisco. Serie Las Culturas Populares de Jalisco. Secretaría 
de Cultura, Gobierno del Estado de Jalisco, Guadalajara.

(2008) "PEPE Lameiras, los indígenas y el indigenismo", en Presencia de José Lameiras en la antropología mexicana, J. E. Zárate, editor. El Colegio de Michoacán, Zamora.

DÍAZ-POLANCO, H. (2006), Elogio de la diversidad. Globalización, multiculturalismo y etnofagia. Siglo Veintiuno Editores, México.

DIETZ, G. (1999), "La comunidad acechada. La región purhépecha bajo el impacto del indigenismo", Relaciones, $N^{\circ} 78$, primavera.

ESCALONA, J. L. (2004), "Reconstrucción de la etnicidad y transformaciones sociales", en Recursos contenciosos. Ruralidad y reformas liberales en México, A. Roth, editor. El Colegio de Michoacán, Zamora.

FLORESCANO, E. (1999), Memoria mexicana. Fondo de Cultura Económica, México.

GARCÍA CANCLINI, N. (1989), Culturas híbridas. CONACULTA, México.

GARIBAY, C. (2008), Comunalismos y liberalismos campesinos. Identidad comunitaria, empresa social forestal y poder corporado en el México contemporáneo. El Colegio de Michoacán, Zamora.

GIL, R. (2006), Fronteras de pertenencia. Hacia la construcción del bienestar y el desarrollo comunitario transnacional de Santa María Tindú, Oaxaca. Juan Pablos Editor / UAM, México.

GÓMEZ CARPINTEIRO, F. J. (2004), "Recursos del pasado. Acción colectiva y sujetos posrevolucionarios en el contexto neoliberal", en Recursos contenciosos. Ruralidad y reformas liberales en México, A. Roth, editor. El Colegio de Michoacán, Zamora.

HERNÁNDEZ, R. A., S. PAZ y M. T. SIERRA (2004), El Estado y los indígenas en tiempos del PAN: Neoindigenismo, legalidad e identidades. CIESAS / Porrúa, México.

KNIGHT, A. (2001), "La política agraria en México desde la Revolución", en Estructuras y formas agrarias en México, del pasado al presente, A. Escobar y T. Rojas, coordinadores. CIESAS / RAN, México.
LAMEIRAS, J. (1990), El Tuxpan de Jalico. Una identidad danzante. El Colegio de Michoacán, Zamora.

LEYVA, X. (2007), "¿Antropología de la ciudadanía?...étnica. En construcción desde América Latina", Liminar. Estudios sociales y humanísticos. Año 5, vol. V, № 1, junio 2007.

LEYVA, X., A. BURGUETE y S. SPEED, coordinadoras (2008), Gobernar (en) la diversidad: experiencias indígenas desde América Latina. Hacia la investigación de co-labor. CIESAS, FLACSO-Ecuador y FLACSO-Guatemala, México.

LISBONA, M. (2005) "Otras voces, otros tojolobales. La pluralidad de una comunidad inventada", en La comunidad a debate. Reflexiones sobre el concepto de comunidad en el México contemporáneo. M. Lisbona, coord., El Colegio de Michoacán / Universidad de Ciencias y Artes de Chiapas, Zamora.

LUCIO, C. et al., (2008), El pueblo nahua de Ayotitlán. Pasado, presente y perspectivas. UdeG / UACI / Taller Editorial La Casa del Mago, Guadalajara.

MARTIN, A. (2002), "El manejo forestal contrastante en dos núcleos agrarios de la Reserva de la Biosfera", Relaciones $\mathrm{N}^{\circ} 89$, invierno.

MEDINA, A. (2005) "Las comunidades corporadas del sur del Distrito Federal. Una primera mirada etnográfica", en La comunidad a debate. Reflexiones sobre el concepto de comunidad en el México contemporáneo, M. Lisbona, coord. El Colegio de Michoacán / Universidad de Ciencias y Artes de Chiapas, Zamora.

MEDINA, A. coord. (2007), La memoria negada de la ciudad de México: sus pueblos originarios. IIA-UNAM / UACM, México.

MORENO, R. (2008), La comunidad indígena coca de Mezcala, el sujeto de la historia en la defensa de la tierra, Tesis de Licenciatura en Historia, Universidad de Guadalajara, Guadalajara.

MUÑOZ, O. (2009), Permanencia en el tiempo. Antropología de la historia en la comunidad purhépecha de Sevina. El Colegio de Michoacán, Zamora.

NAVARRO S. (1999), La isla de Mezcala. La gesta olvidada. Editorial Ágata, S.A de C.V, Guadalajara. 
OCHOA, A. (1985), Los insurgentes de Mezcala. El Colegio de Michoacán, Zamora.

(2006) Los insurrectos de Mezcala y Marcos. El Colegio de Michoacán, Zamora.

PÉREZ VERDÍA, L. (1953), Apuntes Históricos sobre la Guerra de la Indepedencia en Jalisco., I.T.G, Guadalajara.

ROSEBERRY, W. (2004), "'Para calmar los ánimos de los vecinos de este lugar': comunidad y conflicto en el Pátzcuaro porfiriano", Relaciones $\mathrm{N}^{\circ} 100$.

ROTH, A., E. MARTÍNEZ y M. SOSA (2004), "'A nombre de la comunidad'. Política étnica y reforma neoliberal en la Meseta P'urhépecha", en Recursos contenciosos. Ruralidad y reformas liberales en México, A. Roth, editor. El Colegio de Michoacán, Zamora.

SÁNCHEZ, C. (1999), Los pueblos indígenas: del indigenismo a la autonomía. Siglo Ventiuno Editores, México.

VELÁSQUEZ, E. (2004), "Distintas formas de acercamiento a la historia local: la relación entre pasado y presente en una comunidad indígena del Sur de Veracruz", en Recursos contenciosos. Ruralidad y reformas liberales en México, A. Roth, editor. El Colegio de Michoacán, Zamora.

WOLF, E. (1957), "Closed Corporate Peasant Communities in Mesoamerica and Central Java". Southwestern Journal of Anthropology, vol. $1 \mathrm{~N}^{\circ} 13,1957$.

ZÁRATE, J. E. (1996), Los señores de utopía. El Colegio de Michoacán, Zamora.

(2005) "La comunidad imposible", en La comunidad a debate. Reflexiones sobre el concepto de comunidad en el México contemporáneo, M. Lisbona, coord. El Colegio de Michoacán / Universidad de Ciencias y Artes de Chiapas, Zamora.

ZENDEJAS, S. y P. DE VRIES, eds. (1998), Las disputas por el México rural. 2 vols. El Colegio de Michoacán, Zamora.

\section{Documentos}

"RESOLUCIÓN PRESIDENCIAL de reconocimiento y Titulación de bienes comunales del po- blado "MEZCALA", municipio de Poncitlán, Jalisco", Registro Agrario Nacional, 18 agosto 1971.

"ACTA DE Reconocimiento y Titulación de bienes comunales poseídos por la comunidad indígena "MEZCALA", Municipio de Poncitlán, Jalisco, 17 octubre 1974.

"ACTA de Deslinde y Amojonamiento Definitivo", 4 de septiembre de 1997.

"DECLARACIÓN de Mezcala en defensa de la Madre Tierra y la autonomía indígena", Consejo Nacional Indígena, Mezcala, 19 de noviembre de 2006.

"DECLARATORIA de Mezcala", Asamblea General de Comuneros de la Comunidad Indígena de Mezcala, 3 febrero de 2008.

"EL PUEBLO Coca de Mezcala, una Historia de Lucha" trifoliar, 2008.

"ESTATUTO INTERNO Comunidad Indígena Coca Mezcala de La Asunción, Municipio De Ponci tlán, Jalisco". Comunidad Indígena de Mezcala, Mezcala, 7 de junio de 2009.

"LOS COCA de Mezcala siguen vivos", Rocío Moreno, Manuel Jacobo y José Godoy, Hojarasca, 115, noviembre 2006.

"MEZCALA, UN pueblo coca en la defensa de su memoria", Rocío Moreno. Revista Contradecir desde abajo, febrero 2009 http:// contradecir.wordpress.com/2009/02/15/ mezcala-un-pueblo-coca-en-la-defensa-de-sumemoria/

"PLAN DE Desarrollo Urbano del Centro de población de Mezcala de la Asunción", Gaceta, Información con sentido. Órgano informativo del Gobierno Municipal de Poncitlán, № 2, noviembre 2006.

"TÍTULO PRIMORDIAL", Copia mecanografiada y autenticada en La Barca, 6 de diciembre de 1899.

"LEY SOBRE los Derechos y el Desarrollo de los Pueblos y las Comunidades Indígenas del Estado de Jalisco", Congreso del Estado de Jalisco, 30 diciembre 2006. 